\title{
ABYSSAL: A ARTE COMO EXPERIÊNCIA DE ENGAJAMENTO PERCEPTIVO NO ESPAÇO ARQUITETÔNICO
}

\author{
Juliana Pontes Ribeiro*
}

\begin{abstract}
Resumo: Este artigo propõe uma reflexão sobre a obra Abyssal, da artista plástica Regina Silveira, a partir do seu encontro com a arquitetura enquanto elemento estrutural e simbólico. Os conceitos teóricos usados tratam da aquisição de conhecimento acerca do mundo pelas experiências vivenciadas em seu habitar com base em Maurice Merleau-Ponty (1999), Pierre Bourdieu (1993a, 1993b, 2002a, 2002b, 2004, 2009a, 2009b, 2011) e Tim Ingold (1995, 2000, 2011a, 2011b).
\end{abstract}

Palavras-chave: Engajamento perceptivo. Habitus. Arte site-specific. Arquitetura. Regina Silveira.

Regina Silveira, artista plástica brasileira reconhecida por seus trabalhos site-specific intervenções do campo da arte pensadas de maneira específica para sensibilizar um determinado espaço em sua dimensão física e simbólica -, realizou na obra Abyssal (Figura 1), apresentada na Polônia no ano de 2010, um trabalho de inscrição gráfica em um ambiente interno de uma edificação histórica, cuja perspectiva gera uma perturbação na percepção do espaço arquitetônico, especialmente no que se refere ao entendimento das suas dimensões, da sua profundidade e da noção de posicionamento do observador. Essa obra foi tomada neste texto como ponto de convergência e reflexão sobre alguns pensamentos e conceitos propostos pelos autores Maurice Merleau-Ponty (1999), Pierre Bourdieu (1993a, 1993b, 2002a, 2002b, 2004, 2009a, 2009b, 2011) e Tim Ingold (1995, 2000, 2011a, 2011b), por possuir o potencial de revelar ou explicitar algumas das proposições teóricas desses autores por meio da intervenção da arte na experiência de percepção do espaço arquitetônico em análise. Nas palavras da artista:

Abyssal é uma imagem de abismo construida em anamorfose vertical, em que sucessivas fileiras de janelas em grande compressão perspectiva provocam a percepção de um espaço em profundidade, que funcionará como um buraco virtual capaz de proporcionar experiên-

* Doutora em Arquitetura e Urbanismo pela Universidade Federal de Minas Gerais (UFMG). Mestre em Comunicação Social pela UFMG e graduada em Belas Artes pela UFMG. 
cias de estranheza espacial. Nesta imagem digital de grande formato há também uma dimensão temporal, pois com ela quis resgatar - quase arqueologicamente - a memória das janelas do antigo mercado que antes funcionara neste edifício (SILVEIRA, 2012).

Figura 1 - Obra Abyssal de Regina Silvaira, realizada em 2010.

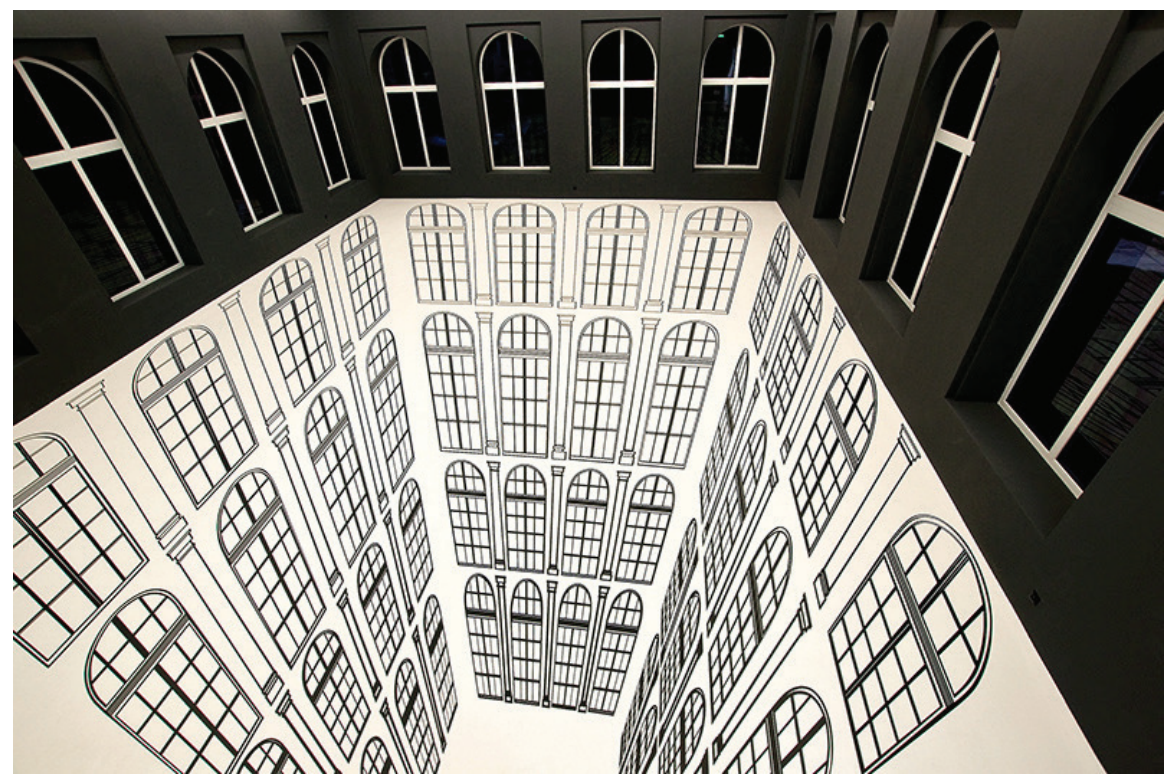

Nota: Vinil adesivo, paredes pintadas e filtros de luz. Atlas Sztuki, Lódz, Polônia.

Fonte: Silveira, 2012.

A discussão teórica desenvolvida a partir da análise dessa obra tem como fundamento a concepção do corpo e dos sentidos como instâncias produtoras de conhecimento, de acordo com Merleau-Ponty (1999); a teoria da práxis e o conceito de habitus, de Pierre Bourdieu (2009a), no qual se verifica a incorporação inconsciente de modos e comportamentos como ponte entre a ação do indivíduo e a estrutura social; e a ruptura com o pensamento dicotômico proposta por Tim Ingold (2000), que pode ser exemplificada na diluição das distinções entre mundo real e mundo simbólico, mundo natural e mundo social, dentro e fora.

Iniciando o percurso de análise descrito acima com a fenomenologia da percepção de Merleau-Ponty (1999), coloca-se em pauta para a observação da obra em questão a ideia de uma relação perceptiva a partir da essência do objeto, o que significa um distanciamento da preocupação com a identificação de relações de causa e efeito advindas do contexto e o foco no objeto da percepção. 0 entendimento do contexto no processo de percepção em Merleau-Ponty (1999) pode ser comparado com a compreensão da noção de planos e pro- 
fundidade de campo em uma imagem fotográfica. Para o autor, é preciso colocar o objeto em foco em detrimento do contexto, ou seja, "é necessário adormecer a circunvizinhança para ver melhor o objeto, e perder em fundo o que se ganha em figura" (MERLEAU-PONTY, 1999 , p. 104). Focar os sentidos em um determinado objeto gera um refinamento na percepção dos planos de uma cena, pois a diferença entre o que está em foco e o que ganhou opacidade ou foi adormecido se torna evidente. Na imagem fotográfica, a consciência dos planos visuais ativos em um contexto só se torna clara quando precisamos isolar um objeto através de parâmetros de luminosidade e foco, identificando em qual camada ou plano ele se encontra, para assim separar esse dos demais níveis que compõem a noção de profundidade de campo de uma cena. A analogia com a fotografia é útil para esclarecer o esforço de decodificação das várias camadas do contexto que atuam na relação entre o sujeito e o objeto, que devem ser percebidas e neutralizadas no intuito de destacar a relação de percepção do sujeito com a essência do objeto e todas as possibilidades que ele traz em si. Além disso, a fotografia é um dos métodos de reconhecimento do espaço usados por Regina Silveira em seu processo criativo.

Observando a obra Abyssal a partir desse pensamento, percebe-se que ela é composta, no mínimo, por dois modos de percepção: a perspectiva do espaço arquitetônico real, com sua estrutura concreta composta pelo chão, paredes e janelas; e a perspectiva perturbadora proposta pela artista, que multiplica as dimensões do espaço real por meio de um mergulho sensorial vertiginoso em uma estrutura arquitetônica virtual. Na linha da fenomenologia da percepção, a consciência do mundo só se revela por meio do estar, ou seja, corpo e sentidos gerando o conhecimento sobre o que é percebido, e não só a mente racional produzindo conclusões sobre dados simplesmente captados pelos órgãos sensoriais. Ao observarmos a obra de Regina Silveira, somos tomados pela confusão entre realidade e ficção, mundo concreto e mundo imaginado, mas todas essas situações são vividas pelo corpo simultaneamente: enquanto pisamos e sentimos a pressão do chão real da edificação, temos a visão de uma continuidade do espaço construído para além da realidade sentida pelos nossos pés. Tato e visão nos dão, ao mesmo tempo, informações contraditórias acerca do ambiente experienciado, indicando as possibilidades do espaço, e não só a sua realidade racionalmente compreendida. A intervenção gráfica da artista no objeto arquitetônico amplia a capacidade desse ambiente de ser uma fonte de vivências diversificadas, deixando sua configuração original como um plano que sustenta a ficção proposta, porém não elimina a sua potência como experiência. 0 que fica evidente aqui é que a racionalização da percepção do espaço concreto não anula a sensação de um espaço virtual vivido. Por meio dessa experiência conjugada, a análise em curso da obra de Regina Silveira pode ser ampliada pela reflexão teórica de Tim Ingold (2000), que propõe a intenção de ruptura com o pensamento dicotômico cartesiano, tendo como recurso o engajamento perceptivo-ativo no contexto vivido. 0 entendimento do espaço por intermédio da ficção proposta pela obra opera em simultanei- 
dade com a percepção da sua realidade concreta, tomada do ponto de vista racional. Sendo assim, as possibilidades de experiências surgem a partir de um engajamento perceptivo-ativo nessa realidade concreta, operado por meio das intervenções e estímulos de caráter sensorial ali realizadas, que constituem uma realidade virtual.

A obra de arte, como campo fértil para a experiência sensivel, fornece condições para a vivência de situações que respondem na prática à questão formulada por Merleau-Ponty: "como ver a partir de um ponto de vista sem estar encerrado nessa perspectiva?" (MERLEAU-PONTY, 1999, p. 104). Em relação a essa indagação, o autor aponta que "olhar um objeto é vir habitá-lo [...]" (MERLEAU-PONTY, 1999, p. 105), situar-se virtualmente em todas as perspectivas possíveis de percepção do objeto. No campo da arte, e mais especificamente na obra Abyssal, essa passa a ser uma possibilidade real, ampliada pela sensação de realidade proporcionada pela experiência sensorial inerente ao contato direto com a obra, que realiza uma simulação de variadas condições de percepção, muitas vezes ainda nem cogitadas pelo sujeito. Os movimentos do observador no espaço o conduzem a uma experiência de imersão ativa nas múltiplas possibilidades da imagem.

A arte site-specific tem a capacidade de desconstruir a imposição de uma única situação de observação como preponderante e reforça o pensamento de Merleau-Ponty, segundo o qual, a descrição de um objeto de acordo com um ponto de vista exclusivo, em uma relação específica com o contexto, não dá conta da sua potência, que reside em múltiplas possibilidades de sentidos na relação com outros pontos de vista, outras formas e outros sujeitos. Não se pode negar as perspectivas sensiveis que o objeto oferece somente porque um único ponto de vista é possível ao sujeito (MERLEAU-PONTY, 1999). Em decorrência da ruptura com uma situação de observação familiar, o estranhamento proposto pela arte colabora para revelar novas perspectivas na relação de percepção entre sujeito e objeto - possibilidades que permanecem invisiveis quando se oferece um ponto de vista único para essa relação. No caso de Abyssal, o senso comum, a princípio, direciona o observador a procurar as referências espaciais tradicionais das habitações e edificações presentes no cotidiano, entre as quais estão o chão, as paredes de sustentação e divisão, o teto e as aberturas, tais como portas e janelas. No entanto, a imagem gráfica sobreposta a essa estrutura padrão nos apresenta outra forma de relação com o espaço por meio da metalinguagem: o posicionamento inusitado de formas da própria arquitetura - no caso, janelas e colunas - no chão, o que normalmente seria improvável. 
Figura 2 - Interações do público com a obra Abyssal, de Regina Silveira.

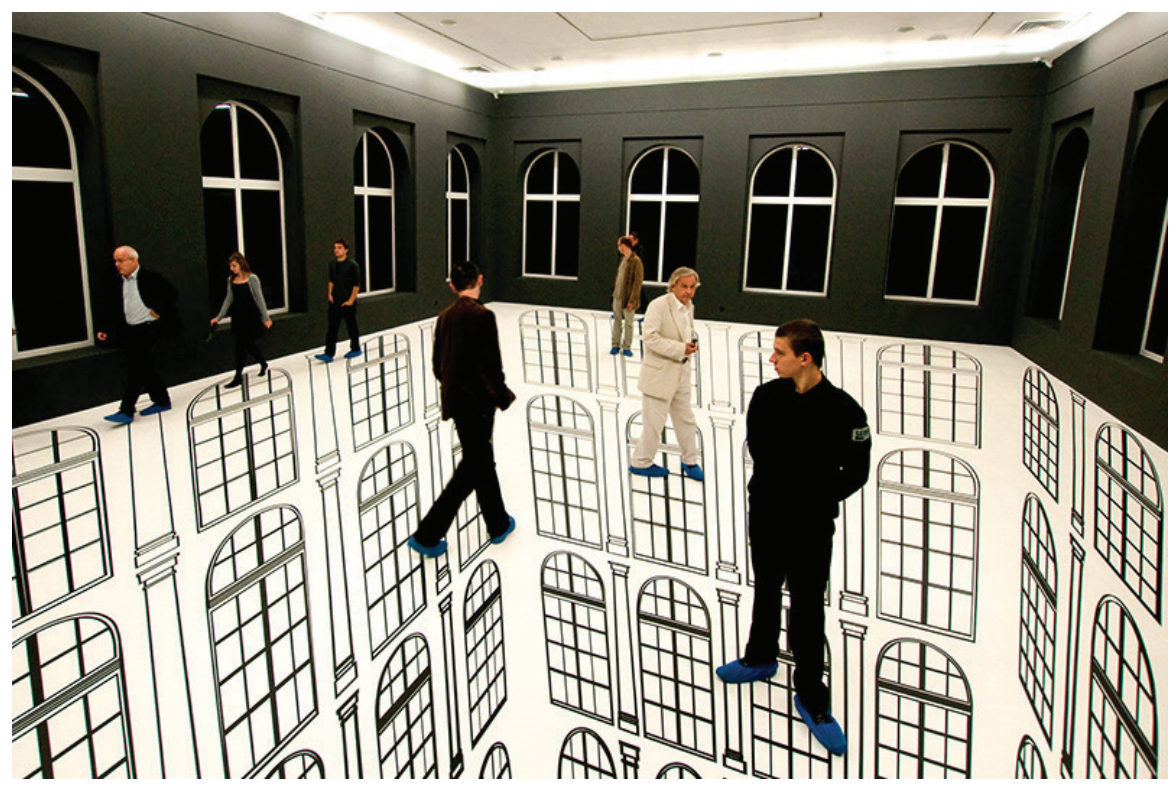

Nota: Vinil adesivo, paredes pintadas e filtros de luz. Atlas Sztuki, Lódz, Polônia.

Fonte: Silveira, 2012.

Esse deslocamento visual das estruturas formais da arquitetura para posições não usuais leva o observador a reagir corporalmente de forma inesperada ao longo do seu percurso pelo ambiente, provocando hesitação e confusão nos seus movimentos habituais. Isso indica que a experiência, mesmo sendo virtual, aponta para novas formas de reconhecimento e adaptação do sujeito por meio da interação corpo-objeto. A consciência da multiplicidade de interações entre sujeito, objeto e contexto responde melhor à ideia dinâmica de processo e continuidade apontada por Ingold (2000), que reforça o ponto de vista de Merleau-Ponty de que "a posição absoluta de um só objeto é a morte da consciência, já que ela imobiliza toda a experiência [...]" (MERLEAU-PONTY, 1999, p. 109). Para pensar a dinâmica das relações, Ingold prefere as noções de conteúdos e processos no lugar de superfícies e formas, pois essas últimas categorias já são vistas em sua totalidade e encerradas em limites preestabelecidos. No caso da obra aqui estudada, o conteúdo das intervenções da artista é planejado, portanto predeterminado, mas o entendimento da sua potencialidade de transformação da percepção do espaço se constrói no processo de interação com o próprio, em que os seus conteúdos se tornam ativos à medida que o sujeito se relaciona corporalmente com o ambiente e percebe o espaço com os seus sentidos. Dessa forma, somente a experiência perceptiva de imersão é capaz de dar sentido ao conteúdo apresentado. 
As noções de superfície e forma, tomadas como referências por Ingold (2000), indicam tanto delimitações de fronteiras entre conteúdo e estrutura aparente quanto a percepção de contornos definidos. Refletindo sobre as formas gráficas em Abyssal, nota-se que elas foram aplicadas sobre a superfície do chão, mas não reforçaram nesse a noção de limite físico que tradicionalmente esse elemento traz. Ao contrário, propuseram uma sensação de continuidade ao sugerir que as paredes e janelas se multiplicam em uma perspectiva de profundidade. Regina Silveira desconstrói, por meio da experiência sensorial, os limites usuais entre o chão e as paredes, formando um novo espaço, composto de uma continuidade que é visual e não estrutural, na qual o sentido dado pela experiência proporciona a interseção entre superfície e conteúdo: o chão, originalmente um limite, apresenta-se como conteúdo contínuo das estruturas verticais da edificação, modificando simbolicamente a sua função de delimitar fronteiras para tornar-se um elemento de conexão entre a realidade concreta e a virtualidade vertiginosa proposta na imagem.

Essa aparente contradição entre a concretude da edificação e a imaterialidade da imagem solicita um retorno à reflexão sobre a ideia de essência a partir de Merleau-Ponty (1999): pode-se pensar que somente na dimensão da experiência é possível compreender que há o "para si" e o "em si" no entendimento da totalidade do objeto. Essa dupla consciência só se realiza para o sujeito no momento em que ele vivencia o que se apresenta na sua própria experiência, situação que faz que ele diferencie o conhecimento que é produzido nessa circunstância daquele que é concebido na especulação racional, comum a quem se coloca na posição de um observador distante. Em uma obra de arte, por exemplo, as sensações e perturbações dos sentidos partem de um referencial comum a todos os observadores (no caso, a estrutura arquitetônica tradicional) para se particularizarem nas experiências individuais. A consciência de que para cada indivíduo existe uma nova situação sensorial e que um mesmo material cognitivo pode se desdobrar em múltiplas perspectivas relacionais explicita a convivência simultânea do "para si" (o que uma situação significa em cada experiência individual) e do "em si" (as múltiplas possibilidades perceptivas contidas em uma dada situação). Na obra Abyssal, a compreensão racional de que o observador circula por uma edificação arquitetônica tradicional convive com estímulos sensoriais capazes de perturbar essa certeza de realidade.

Quando lidamos com a arquitetura tradicional somos tomados por nosso hábito de circulação e uso desses espaços, que se relaciona com as repetições cotidianas movidas pelos fenômenos e pela experiência, citadas por Merleau-Ponty (1999). Essa forma de movimentação pode ser associada não só ao hábito de circulação em espaços arquitetônicos comuns, mas também ao entendimento social do uso e função das estruturas de uma edificação (portas, janelas, divisórias, chão e teto). Essa compreensão social dos ambientes relaciona-se também com o conceito de habitus em Bourdieu (2002a), de acordo com o qual o sujeito incorpora a estrutura e as determinações do campo social por meio da prática e essas pas- 
sam a exercer influência em seus atos e comportamentos como uma força ou predisposição inconsciente. Em uma intervenção como a feita pela artista Regina Silveira, essas funções são repensadas e a arquitetura se apresenta sob nova forma para o observador/usuário, modificando a sua maneira de se relacionar com o ambiente $e_{1}$ consequentemente, o seu hábito de circulação espacial.

No que diz respeito ao conceito de habitus, de Bourdieu (2002a), podemos associar a situação proposta na obra Abyssal com a capacidade de habituar-se a novas condições, nesse caso, reterritorializar a noção de espaço a partir de uma prática conjugada com um sistema de pensamento. Não há somente uma ruptura com o mecanicismo da ação usual de circulação, mas há também uma prática associada a uma reflexão sobre a dimensão real e simbólica do espaço arquitetônico e sua potência como instrumento de reconfiguração das relações ali instauradas. 0 habitus não é um esquema a priori aplicado à compreensão da experiência ou manifesto nela: "Em outras palavras, o habitus não é expressado na prática, mas ele subsiste nela"1 (INGOLD, 2000, p. 162, tradução nossa). Construído no domínio prático exercido por nossos corpos, o habitus se relaciona com uma habilidade incorporada, adquirida não por meio da instrução formal, mas por uma rotina de realização de tarefas específicas.

Considerando a dimensão do tempo, a relação de Bourdieu (2002a) é com o passado, pois, para o autor, o novo só se faz a partir de algo já instituído historicamente. Nesse sentido, podemos entender que a nova experiência com o espaço na obra Abyssal surge da intervenção em uma construção social anterior. É sobre uma noção anterior de ocupação física de uma edificação que redimensionamos a nossa nova experiência com a arquitetura. Além disso, a imagem gráfica sobreposta à arquitetura, nesse caso adesivada sobre o chão original, recupera modelos tradicionais de colunas e janelas que fazem parte da memória ou do repertório comum de muitos que circularam pela obra, colocando em jogo também referências históricas e dados culturais, como, por exemplo, a fachada do antigo mercado que existia nesse edifício. Em Merleau-Ponty (1999), percebe-se uma tentativa de dar mais autonomia à percepção do sujeito, pois a fenomenologia foca a experiência do tempo presente, o vivido carnalmente. A dinâmica do corpo imerso na obra analisada é um fator preponderante para o acionamento da reconstrução simbólica do espaço na condição da experiência. Mesmo partindo de um substrato social dado, a autonomia da percepção apontada pelo autor pode ser verificada na situação de confusão sensorial momentânea provocada pela perspectiva desconcertante e pela visão de uma extensão simulada da edificação. A entrega instantânea do corpo à reação sensória causada por uma perturbação de ordem visual constitui uma porta para a compreensão de que aquele espaço construido traz muito mais possibilidades de interação do que as situações previsiveis do cotidiano.

1 - No original: "In other words, the habitus is not expressed in practice, it rather subsists in it". 
Como objeto de arte, a obra Abyssal exige ainda uma percepção guiada por uma intenção estética, que implica a consciência da forma de maneira mais intensa e impactante, antecipando a percepção da função. Já foi mencionado aqui que as janelas e colunas grafadas no chão para compor a obra foram inspiradas nas antigas formas do edifício em questão, extraídas de um universo compartilhado de modelos formais criados pela arquitetura ocidental. De acordo com Bourdieu (2011), na percepção estética predomina o entendimento das formas a partir do acionamento de um conhecimento específico do campo da arte, o que implica o reconhecimento dos códigos desse campo, ou seja, uma competência específica adquirida pela educação. Nesse sentido, esses modelos de estruturas arquitetônicas padronizadas que aparecem nos desenhos da artista recuperam essa bagagem de conhecimento, mas a vertigem experienciada na interação com a obra evoca a percepção vivida no cotidiano em tempo presente, advinda de uma lógica social compartilhada, e não de uma competência para o entendimento do campo da arte. A potência de uma obra dessa natureza está justamente em sensibilizar tanto os iniciados quanto os observadores comuns, desconcertando os primeiros pela ideia de que os padrões históricos da arquitetura, que estão subjacentes à nossa concepção de espaço, podem ser acionados esteticamente de forma transgressora; e perturbando os segundos por fazer os elementos funcionais de uma edificação perderem esse aspecto ao serem deslocados de suas posições operacionais para ocuparem um novo papel no sentido da experiência do habitar.

A educação pela atenção, proposta por Tim Ingold (2000), tem a sua sustentação na ideia de engajamento no mundo, que passa por práticas que participam tanto da condição material quanto da condição simbólica de uma realidade. 0 engajamento pressupõe a imersão, 0 desenvolvimento de habilidades na prática e a percepção ativa para o conhecimento corporificado, realizado com o corpo. Por ser uma obra site-specific, planejada para ocupar um espaço determinado, Abyssal é uma intervenção capaz de imbuir esse espaço arquitetônico de uma multiplicidade de possíveis experiências, propiciando o engajamento criativo do observador no processo de circulação no espaço delimitado pela obra. A informação visual acrescida ao ambiente é um ponto de partida para que a relação entre o sujeito e o objeto arquitetônico se torne inventiva por meio da aquisição performática de um novo saber sobre o habitar naquele local.

A proposta de Ingold (2000) de engajamento na ação e de desenvolvimento de habilidades nesse processo traz uma reflexão sobre as áreas criativas e as áreas projetuais, como a arquitetura, o design e o artesanato. As formas impostas a partir de modelos concebidos racionalmente, que são estruturas mentais projetadas, muitas vezes surgem de um pensamento que representa mais a cultura sobreposta à matéria bruta do que uma forma resultante da observação dos processos relacionais entre o homem e o ambiente que o cerca. A imposição projetual acaba por determinar formas destinadas ao uso cotidiano que são pensadas de maneira independente dos processos de vida e da relação natural com os ambientes, criando 
algumas vezes objetos e estruturas que não exercem um papel de real aproximação entre os sujeitos e o mundo ao seu redor. Em vista disso, essas formas projetadas são, muitas vezes, modificadas no processo de sua execução material, em que ocorre o embate com a concretude da matéria, que é a condição de produção que geralmente prevalece sobre o modelo mental gerador da forma.

Como propõe Ingold (2011b) em uma conferência, é preciso perceber a tensão entre o sonho e a materialização, o fluxo contínuo imaginativo e a restrição material construtiva. Nessa mesma direção, está o desafio de pensar a distância entre o ambiente experienciado e o ambiente projetado, visto que o primeiro pede a improvisação criativa para responder às circunstâncias da vida presente e o segundo se baseia em experiências passadas para preconceber formas que vislumbram a inovação. Em Regina Silveira, a arte questiona essas imposições no campo da arquitetura sugerindo, por exemplo, uma inversão da lógica urbana: em lugar das edificações se imporem por sua verticalidade ascendente monumental, desequilibra-se o observador por conduzi-lo à visão de um abismo arquitetônico aos seus pés. 0 que foi projetado e executado como arquitetura se encontra diante de um cenário criativo para a experiência, na qual se utiliza o próprio método projetual como estratégia de desconstrução da realidade.

\section{Abyssal: art as an experience of perceptive engagement in the architectural space}

Abstract: This article proposes a reflection on the work Abyssal, by the plastic artist Regina Silveira, from its encounter with architecture as a structural and symbolic element. The theoretical concepts used regard the acquisition of knowledge about the world through the experiences lived in its dwelling, based on Maurice Merleau-Ponty (1999), Pierre Bourdieu (1993a, 1993b, 2002a, 2002b, 2004, 2009a, 2009b, 2011) and Tim Ingold (1995, 2000, 2011a, 2011b).

Keywords: Perceptive engagement. Habitus. Site-specific art. Architecture. Regina Silveira.

\section{REFERÊNCIAS}

BOURDIEU, P. Structures and the habitus. In: BOURDIEU, P. Outline of a theory of practice. Cambridge: Cambridge Press, 1993a. p. 72-95.

BOURDIEU, P. Structures, habitus, power: basis for a theory of symbolic power. In: BOURDIEU, P. Outline of a theory of practice. Cambridge: Cambridge Press, 1993b. p. 159-197.

BOURDIEU, P. A gênese dos conceitos de habitus e de campo. In: BOURDIEU, P. O poder simbólico. Rio de Janeiro: Bertrand Brasil, 2002a. p. 9-16. 
BOURDIEU, P. Sobre o poder simbólico. In: BOURDIEU, P. O poder simbólico. Rio de Janeiro: Bertrand Brasil, 2002b. p. 59-73.

BOURDIEU, P. Espaço social e poder simbólico. In: BOURDIEU, P. Coisas ditas. São Paulo: Brasiliense, 2004. p. 149-168.

BOURDIEU, P. Estruturas, habitus, práticas. In: BOURDIEU, P. O senso prático. Petrópolis: Vozes, 2009a. p. 86-107. v. 1.

BOURDIEU, P. A crença e o corpo. In: BOURDIEU, P. O senso prático. Petrópolis: Vozes, 20096. p. 108-132. v. 1.

BOURDIEU, P. Modos de produção e modos de percepção artísticos. In: BOURDIEU, P. A economia das trocas simbólicas. São Paulo: Perspectiva, 2011. p. 269-294.

INGOLD, T. Humanidade e animalidade. Revista Brasileira de Ciências Sociais, v. 10, n. 28, p. 39-54, 1995.

INGOLD, T. The perception of the environment: essays in livelihood, dwelling and skill. London: Routledge, 2000.

INGOLD, T. Being alive: essays on movement, knowledge and description. London: Routledge, 2011a.

INGOLD, T. CONFERÊNCIA, 2011, Belo Horizonte. Designing environments for life. Belo Horizonte: UFMG, $2011 b$.

MERLEAU-PONTY, M. A fenomenologia da percepção. 2. ed. São Paulo: Martins Fontes, 1999.

SILVEIRA, R. Regina Silveira. Disponivel em: http://www.reginasilveira.com. Acesso em: 7 jul. 2015.

SILVEIRA. R. Instalação. Abyssal. 2012. Disponivel em: https://reginasilveira.com/filter/ instala\%C3\%A7\%C3\%A3o/ABYSSAL. Acesso em: 7 jul. 2015. 